\title{
Numerical Classification of Mycobacterium farcinogenes, Mycobacterium senegalense and Related Taxa
}

\author{
By MALIN RIDELL ${ }^{1}$ AND M. GOODFELLOW 2 * \\ ${ }^{1}$ Institute of Medical Microbiology, University of Göteborg, S-413 46 Göteborg, Sweden \\ ${ }^{2}$ Department of Microbiology, The University, Newcastle upon Tyne NE1 7RU, U.K.
}

(Received 15 June 1982)

\begin{abstract}
Sixteen strains designated Mycobacterium farcinogenes, fifteen Mycobacterium senegalense, and ten Nocardia farcinica were, together with strains of Mycobacterium and Nocardia, subjected to numerical phenetic analyses using 96 unit characters. The data were examined using the simple matching $\left(S_{S M}\right)$, Jaccard $\left(S_{J}\right)$ and pattern $\left(D_{P}\right)$ coefficients and clustering achieved using the unweighted average linkage algorithm. Cluster composition was not markedly affected by the coefficient used or by test error, estimated at $2.5 \%$. The $N$. farcinica strains formed a distinct and homogeneous cluster in an aggregate taxon corresponding to the genus Nocardia. The M.farcinogenes and $M$. senegalense strains were recovered in well-defined and homogeneous phena within the genus Mycobacterium. Mycobacterium senegalense consistently showed a high overall similarity with clusters equated with $M$. chelonei and $M$. fortuitum, while the $M$. farcinogenes cluster was not closely associated with any of the mycobacterial clusters. The results are discussed in the light of other developments in the taxonomy of the bovine farcy bacteria.
\end{abstract}

\section{INTRODUCTION}

Mycobacterium farcinogenes was proposed by Chamoiseau (1973) who recognized two subspecies, tchadense and senegalense, which encompassed strains able to cause farcy, a serious disease of African bovines (Chamoiseau, 1969, 1972). The subspecies were subsequently raised to species status as Mycobacterium farcinogenes and Mycobacterium senegalense, respectively (Chamoiseau, 1979), and were distinguished on the basis of DNA homology, growth rate, biochemical activity and histopathological behaviour. In the absence of comparative studies little is known, however, of the relationship of $M$. farcinogenes and $M$. senegalense to established species of Mycobacterium, or to Nocardia farcinica Trevisan which has been confused with the bovine farcy strains (Magnusson \& Mariat, 1968; Ridell, 1975; Magnusson, 1976; Orchard \& Goodfellow, 1980).

Chemical and serological analyses show that $N$. farcinica can be clearly distinguished from both $M$. farcinogenes and $M$. senegalense (Ridell, 1981; Ridell et al., 1982). Thus, strains of the former contain a single mycolic acid methyl ester and non-hydroxylated fatty acid methyl esters characteristic of true nocardiae (Minnikin \& Goodfellow, 1980) and have more precipitinogens in common with nocardiae, as opposed to mycobacteria. However, nocardiae and mycobacteria have many physiological and biochemical properties in common and simple diagnostic tests are needed to distinguish $N$. farcinica from the two mycobacterial taxa. Lipid and serological data also suggest that $M$. farcinogenes and $M$. senegalense are closely related to one another and to $M$. fortuitum, $M$. phlei and $\boldsymbol{M}$. smegmatis. On the basis of mycolic acid analysis, $\boldsymbol{M}$. farcinogenes and $M$. senegalense cannot be separated as each contains $\alpha$-mycolates and characteristic polar mycolates previously only found in $M$. fortuitum and $M$. smegmatis. The serological data reinforce these affinities and also suggest that $M$. farcinogenes and $M$. senegalense might be classified in a 
single species. Ridell and her colleagues concluded, however, that detailed studies using other modern taxonomic methods were required to unravel the relationship between the two bovine farcy taxa.

Numerical phenetic surveys, with their emphasis on many independent characters, have established a framework for the intrageneric classification of the genera Mycobacterium (Goodfellow \& Wayne, 1982) and Nocardia (Orchard \& Goodfellow, 1980; Goodfellow \& Minnikin, 1981 $a$ ). Numerical taxonomy also gives results that are valuable for identification, and a computer probability matrix exists for the identification of unknown slow growing mycobacteria (Wayne et al., 1980). In the present study, good representative strains of $M$. farcinogenes, $M$. senegalense and $N$. farcinica, and marker strains of related taxa, were compared using numerical taxonomic techniques.

\section{METHODS}

Strains. The 82 test strains were obtained from either private or public culture collections (Table 1). Where possible, type strains were included. More detailed information on the strains can be found elsewhere (Ridell, 1975; Orchard \& Goodfellow, 1980; Ridell et al., 1982). All of the cultures were maintained on Löwenstein-Jensen $(\mathrm{L}-\mathrm{J})$ slopes at room temperature.

Media. The L-J media, Rogosa medium, Sabouraud agar, blood agar and gelatin were all provided by Dr E. Falsen, Section for Microbiological Media, Institute of Medical Microbiology, Göteborg, Sweden. The glucose nutrient agar was based on material from Oxoid.

Collection of data. Each strain $(t)$ was examined for 108 unit characters ( $n$; Table 2 ). Unless otherwise stated, the strains were incubated at $37^{\circ} \mathrm{C}$ and examined after $7,14,21$, or in the case of poorly growing cultures, $28 \mathrm{~d}$. Data for computation were taken from final test readings.

Colony morphology and pigmentation. Colonial properties were observed on glucose nutrient agar plates.

Biomedical and degradative tests. Cultures were examined for $3 \mathrm{~d}$ arylsulphatase (Wayne, 1961), catalase $68^{\circ} \mathrm{C}$ (Kubica \& Pool, 1960; David, 1976), $\beta$-lactamase (Backelin et al., 1973), nitrophenoloxidase (Bönicke \& Juhasz, $1965)$ and nitrate reductase (Virtanen, 1960 ; David, 1976). Adenine $(0.5 \%, w / v)$, elastin $(0 \cdot 1 \%$, w/v), guanine $(0.2 \%, \mathrm{w} / \mathrm{v})$, hypoxanthine $(0.5 \%, \mathrm{w} / \mathrm{v})$, testosterone $(0.1 \%, \mathrm{w} / \mathrm{v})$, tyrosine $(0.5 \%, \mathrm{w} / \mathrm{v})$ and xanthine $(0.4 \%, \mathrm{w} / \mathrm{v})$ were examined in Gordon's (1967) basal medium. In these tests, the disappearance of the insoluble compounds from underneath and around areas of growth was scored as a positive result. Starch $(1 \%, w / v)$ decomposition was detected after Gordon \& Mihm (1957). The haemolysis test was performed using broth agar enriched with defibrinated horse blood $(10 \%, \mathrm{v} / \mathrm{v})$.

Inhibition tests. Resistance to lysozyme and rifampin was performed after Gordon \& Barnett (1977). The ability of the strains to grow in the presence of various concentrations of the remaining antimicrobial and chemical agents was examined using L-J and glucose nutrient agar plates, respectively.

Tolerance tests. Cultures were examined for their ability to grow at $12{ }^{\circ} \mathrm{C}$ and $50^{\circ} \mathrm{C}$ on glucose and nutrient agar and at $45^{\circ} \mathrm{C}$ on $\mathrm{L}-\mathrm{J}$ medium. Survival at $60^{\circ} \mathrm{C}$ was determined by inoculating glucose broths, incubating at $37^{\circ} \mathrm{C}$ until good growth was obtained, then heating the broth suspensions in a water bath at $60^{\circ} \mathrm{C}$ for $4 \mathrm{~h}$ before plating out a loopful of the heated suspensions on to $\mathrm{L}-\mathrm{J}$ medium and incubating at $37^{\circ} \mathrm{C}$. Tolerance to pH was examined in glucose nutrient broth supplemented with horse serum $(13 \%, \mathrm{v} / \mathrm{v})$ and buffered with phosphate buffers.

Growth tests. The organisms were examined for their ability to grow on Sabouraud agar, Rogosa medium and in gelatin broth. Visible growth after $24 \mathrm{~h}$ and $5 \mathrm{~d}$ and the number of colonies on plates were determined by inoculating glucose nutrient agar with $0.1 \mathrm{ml}$ of a suspension containing a loopful ( $4 \mathrm{~mm}$ diam. loop) of bacteria suspended in $2 \mathrm{ml}$ phosphate buffer.

Coding of data. Most of the characters existed in one of two mutually exclusive states and were scored plus $(+)$ or minus ( - ). Qualitative multistate characters, such as pigmentation and some of the colony characters, were scored plus for the character state exhibited and minus for the alternatives. Quantitative multistate characters, mainly derived from the biochemical and inhibition tests, were scored using the additive method of Sneath \& Sokal (1973). Resistance to the antimicrobial and chemical agents was scored as + . Twelve unit characters were deleted from the data matrix as all of the strains gave identical $(++$ or -- ) results. The final $n \times t$ table, therefore, contained data for 82 strains and 96 unit characters. The binary data were stored on standard IBM punch cards.

Computation. Data were analysed using the Clustan 1A program (Wishart, 1978) on an IBM 370/180 computer using the simple matching coefficient ( $S_{S M}$; Sokal \& Michener, 1958), which includes both positive and negative matches, the Jaccard coefficient $\left(S_{J}\right.$; Sneath, 1957) which counts positive matches only, and the pattern coefficient $\left(D_{P} ;\right.$ Sneath, 1968), which seeks to allow for differences in growth rates, incubation periods and similar factors which might contribute to overall dissimilarity between strains. In all cases, data were sorted using the unweighted average linkage (UPGMA) algorithm (Sneath \& Sokal, 1973) and presented as abbreviated dendrograms (Figs 1-3). 
Table 1. Designation and source of strains assigned to clusters in the $S_{S M} / U P G M A$ analysis

Strains assigned to cluster 1 (Mycobacterium marinum)

*GA411 Mycobacterium marinum, ATCC 927

GA012 M. marinum, L. Zettergren, University of Göteborg, Göteborg, Sweden

Strains assigned to cluster 2 (Mycobacterium avium)

GA009 Mycobacterium avium, G. Penso, Istituto Superiore di Sanità, Rome, Italy, Ceppo Faisan IV

GA655 M. avium, ATCC 19421

Strains assigned to cluster 3 (Mycobacterium scrofulaceum)

GA027

GA631

Mycobacterium scrofulaceum, G. Penso, Ceppo chauviré

M. scrofulaceum, ATCC 25214

Strains assigned to cluster 4 (Mycobacterium kansasii)

GA120 Mycobacterium kansasii, E. H. Runyon, Salt Lake City, Utah, U.S.A., Pl6

GA670 M. kansasii, ATCC 25221

Strains assigned to cluster 5 (Mycobacterium vaccae)

*GA681 Mycobacterium vaccae, ATCC 15483

GA333, M. vaccae, R. N. Bönicke, Forschungsinstitut Borstel, F.R.G.,

GA335 SN901, SN967

*GA363

GA447

GA922

GA921

GA950

*GA923

GA948

GB047

GA949

GA951

GA959

GB052

GA967

GB042

GB040

GA968

GB046

GA969

GB045

GA932

GA882

GA931

GA883

GA939

GA940

*GA924

GA884

GB053

GA935

GA920

GA786

GA816

GB043
Strains assigned to cluster 6 (Mycobacterium gastri)

Mycobacterium gastri, ATCC 15754

M. gastri, L. G. Wayne, Veterans Administration Hospital, Long Beach, California,

U.S.A., W465

Strains assigned to cluster 7 (Mycobacterium farcinogenes)

Mycobacterium farcinogenes, M. P. Lechevalier, Rutgers University, New Brunswick, N.J.,

U.S.A., IP740. M. Goodfellow, M261

M. farcinogenes, M. P. Lechevalier, IP736. M. Goodfellow, M260

M. farcinogenes, E. H. Runyon R428; IP743. M. Goodfellow, M276

$M$. farcinogenes, NCTC 10955. M. Goodfellow, M262

M. farcinogenes, E. H. Runyon, R415; R. E. Gordon, 1226. M. Goodfellow, M271

$M$. farcinogenes, M. P. Lechevalier, 1234. M. Goodfellow, N716

$M$. farcinogenes, E. H. Runyon, R425; IP738. M. Goodfellow, M272

M. farcinogenes, E. H. Runyon, R429; IP744. M. Goodfellow, M277

$M$. farcinogenes, E. H. Runyon, R422; IP735. M. Goodfellow, M269

M. farcinogenes, M. P. Lechevalier, 1244. M. Goodfellow, N720

$M$. farcinogenes, E. H. Runyon, R414; IP739. M. Goodfellow, M273

$M$. farcinogenes, R. E. Gordon, Rutgers University, New Brunswick, N.J., U.S.A., 1242.

M. Goodfellow, N711

M. farcinogenes, R. E. Gordon, 1223. M. Goodfellow, N709

$M$. farcinogenes, E. H. Runyon, R427; IP742. M. Goodfellow, N275

M. farcinogenes, M. P. Lechevalier, 1224. M. Goodfellow, N715

Strains assigned to cluster 8 (Mycobacterium senegalense)

Mycobacterium farcinogenes, E. H. Runyon, R147. M. Goodfellow, M280

Mycobacterium senegalense, R. E. Gordon, 1363. M. Goodfellow, N714

$M$. senegalense, E. H. Runyon, R456. M. Goodfellow, M283

$M$. senegalense, M. Magnusson, Statens Seruminstitut, Copenhagen, Denmark, 875.

M. Goodfellow, N727

M. senegalense, E. H. Runyon, R455. M. Goodfellow, M282

$M$. senegalense, M. Magnusson, 876. M. Goodfellow, N728

$M$. senegalense, E. H. Runyon, R408; R. E. Gordon, 1361, IP397. M. Goodfellow, M265

$M$. senegalense, E. H. Runyon, R409; R. E. Gordon, 1362; IP443C

$M$. senegalense, NCTC 10956. M. Goodfellow, M263

M. senegalense, E. H. Runyon, 410; R. E. Gordon, 1364. M. Goodfellow, N729

$M$. senegalense, M. P. Lechevalier, 931. M. Goodfellow, N721

$M$. senegalense, E. H. Runyon, R148. M. Goodfellow, M279

$M$. senegalense, NCTC 4524. M. Goodfellow, M259

M. senegalense, I. Juhlin, Malmö allmänna sjukhus, Malmö, Sweden 396/193.

M. Goodfellow, N696

M. senegalense, R. N. Bönicke, SN5701. M. Goodfellow, N723

M. senegalense, R. E. Gordon, 1360. M. Goodfellow, N712 
Table 1. (continued)

Strains assigned to cluster 9 (Mycobacterium chelonei)

${ }^{*}$ GA717 Mycobacterium chelonei, NCTC 946

GA716 M. chelonei, ATCC 19977

Strains assigned to cluster 10 (Mycobacterium fortuitum)

GA728

GA730

*GB178

GA023

*GB191

GA732

GA733

GB734

${ }^{*}$ GB735

GB736

*GA819

*GA826

*GA919

GA879

GA886

GA827

GA880

GA885

GB293

GA988

GB002

GA991

GA873

GA852

GA869

GA987

GA990

GA984

GA985

GA999

GA986

*GA875

GA979

*GA976

GA976
GA982

GB003

Mycobacterium fortuitum, NCTC 2291; ATCC 9821

M. fortuitum, NCTC 10395; ATCC 6842

$M$. fortuitum, NCTC 10394; ATCC 6841

$M$. fortuitum, G. Penso, 456

Strains assigned to cluster 11 (Mycobacterium phlei)

Mycobacterium phlei, NCTC 8151; ATCC 11758

M. phlei, NCTC 8156

$M$. phlei, NCTC 10260

Strains assigned to cluster 12 (Mycobacterium smegmatis)

Mycobacterium smegmatis, NCTC 3821

M. smegmatis, NCTC 8159; ATCC 19420

M. smegmatis, NCTC 10265 ; ATCC 14468

Strains assigned to cluster 13 (Nocardia farcinica)

Nocardia farcinica, R. N. Bönicke, EB1957; ATCC 3318. M. Goodfellow, N699

N. farcinica, M. Magnusson, 752; ATCC 3318. M. Goodfellow, N700

N. farcinica, M. P. Lechevalier, ATCC 3318. M. Goodfellow, M258

N. farcinica, M. Magnusson, 654; ATCC 6864. M. Goodfellow, N704

N. farcinica, M. Magnusson, 952

N. farcinica, M. Magnusson, 753; ATCC 3399. M. Goodfellow, N701

N. farcinica, M. Magnusson, 884. M. Goodfellow, N705

N. farcinica, M. Magnusson, 878. M. Goodfellow, N707

N. farcinica, M. Magnusson, 845

Nocardia asteroides, S. G. Bradley, Virginia Commonwealth University, Richmond, Va, U.S.A.,

VAC 426. M. Goodfellow, N668

$N$. asteroides, M. Goodfellow, N906

N. farcinica, S. G. Bradley, VAC 324. M. Goodfellow, N670

Strains assigned to cluster 14 (Nocardia asteroides)

Subcluster 14A

Nocardia otitidis-caviarum, ATCC 14629. M. Goodfellow, N36

N. otitidis-caviarum, R. E. Gordon, 737

Nocardia asteroides, R. E. Gordon, NCTC 659

Subcluster 14B

$N$. asteroides, M. Goodfellow, N861

N. asteroides, K. P. Schaal, Hygiene-Institute, University of Cologne, F.R.G., N23.

M. Goodfellow, N692

Subcluster $14 \mathrm{C}$

N. asteroides, K. P. Schaal, N2. M. Goodfellow, N688

N. asteroides, K. P. Schaal, N3. M. Goodfellow, N689

N. asteroides, K. P. Schaal, N10. M. Goodfellow, N904

N. asteroides, NCTC 8595; ATCC 14759. M. Goodfellow, N13

Subcluster 14D

N. asteroides, ATCC 19247. M. Goodfellow, N317

N. asteroides, M. Hutchinson, Water Research Centre, Medmenham, Bucks., U.K.

M. Goodfellow, E9

Strains assigned to cluster 15 (Nocardia brasiliensis)

Nocardia brasiliensis, ATCC 19296. M. Goodfellow, N318

N. brasiliensis, NCTC 10300; ATCC 19295. M. Goodfellow, N14

Single member cluster

* Type strains. Sources: ATCC, American Type Culture Collection, Rockville, Md., U.S.A.; IP, Institut Pasteur, Paris, France; NCTC, National Collection of Type Cultures, London, U.K. 


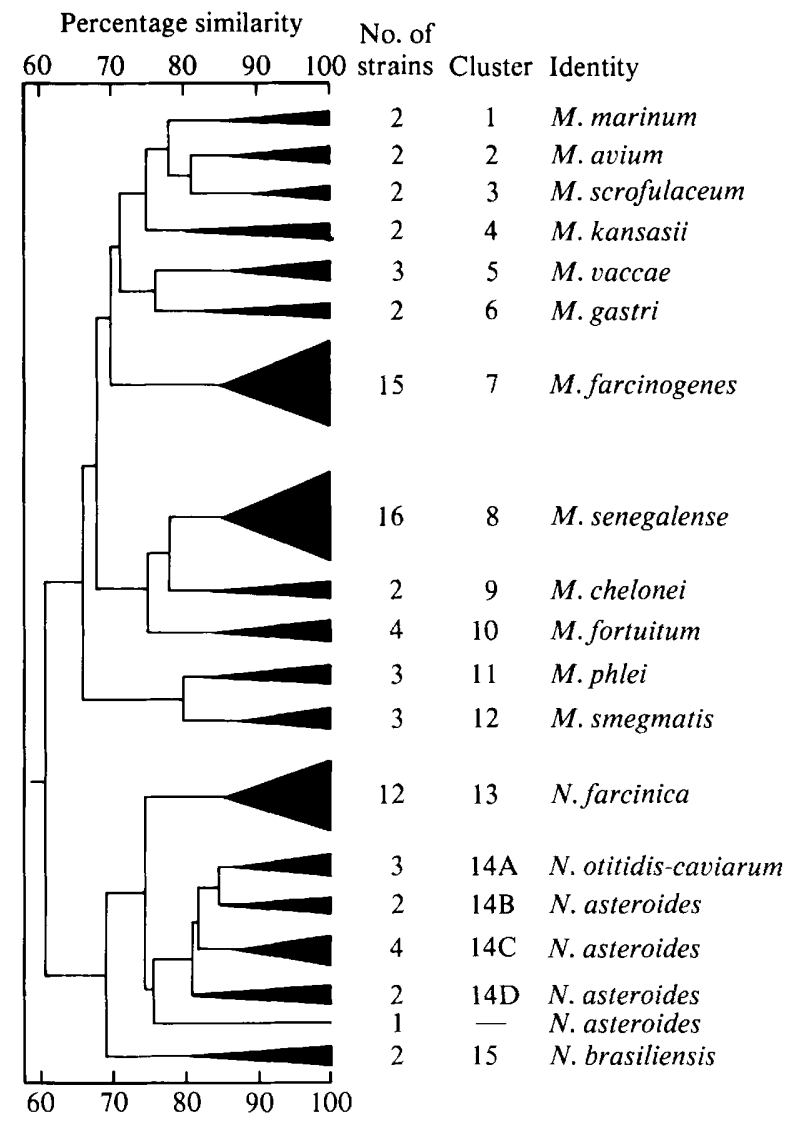

Fig. 1. A simplified dendrogram showing relationships between clusters and subclusters based on the $S_{S M}$ coefficient and unweighted average linkage algorithm.

\section{RESULTS}

Test error and final data matrix

The inclusion of three strains of $N$. farcinica ATCC 3318 in the study (Table 1) made it possible to get an approximate estimate of the experimental test error. The triplicate cultures united at the $95 \%$ similarity $(S)$ level indicating that the average probability $(P)$ of an erroneous test result was around $2.5 \%$. Twelve tests were deleted from the data matrix as they had no separation value. None of the strains degraded adenine, blood, elastin, guanine or starch, nor were they able to grow at $\mathrm{pH} 3 \cdot 3, \mathrm{pH} 11 \cdot 3$, or on Rogosa medium. In contrast, all of the cultures grew in the presence of crystal violet $(0.0001 \%, \mathrm{w} / \mathrm{v})$, phenol $(0.001,0.01 \%, \mathrm{w} / \mathrm{v})$ and sodium azide $(0.001 \%, \mathrm{w} / \mathrm{v})$.

\section{Clustering of strains using the $S_{S M}$ coefficient with the UPGMA algorithm}

Eighty-one of the eighty-two strains were recovered in fifteen clusters defined at the $82 \% S$ level (Table 1 ; Fig. 1). At the $66 \% S$-level the Mycobacterium and Nocardia strains separated into two aggregate clusters. The nocardiae fell into three clusters, the largest of which was equated with $N$. farcinica. Thus, cluster 13 contained all 10 strains of $N$. farcinica and $N$. asteroides GA988 and GB002. This cluster was clearly separated from all of the remaining phena including those equated with $N$. asteroides and $N$. brasiliensis. The $N$. asteroides cluster was divided into four subclusters one of which, 14A, contained $N$. otitidis-caviarum GA852 and GA873 and $N$. asteroides GA896. The final strain received as $N$. asteroides, GB003, formed a single member cluster which shared its highest affinities with strains assigned to cluster 14 . 


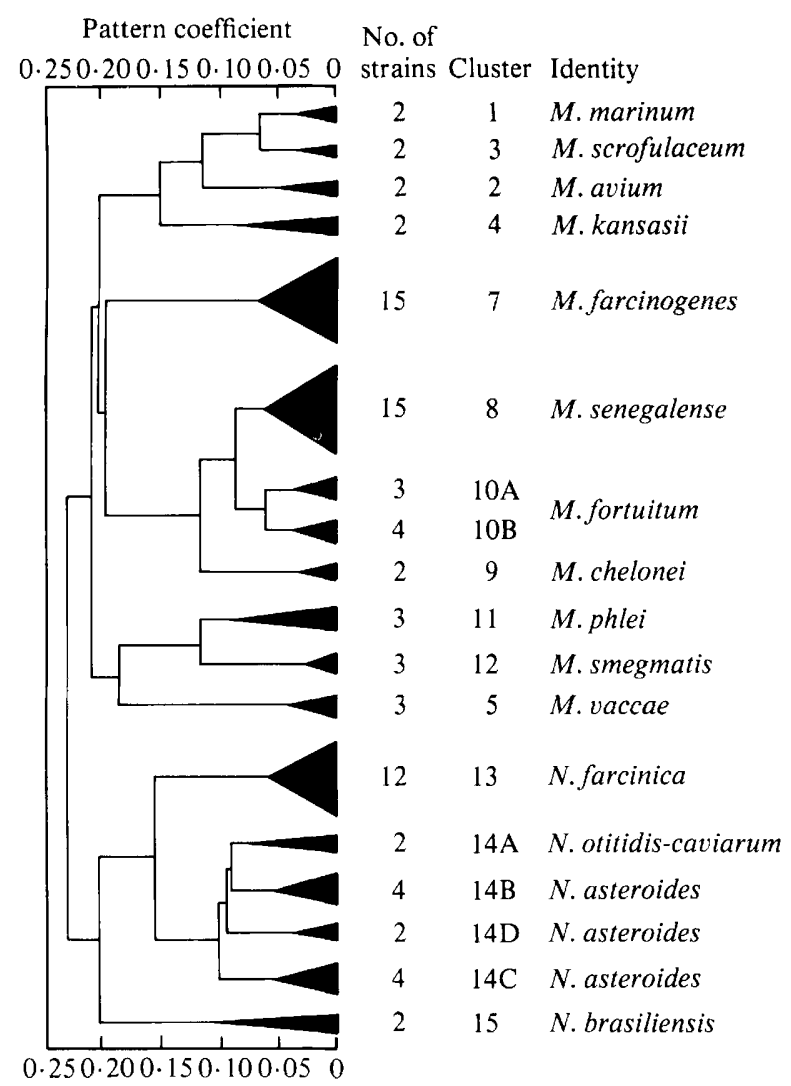

Fig. 2. A simplified dendrogram showing the relationships between clusters and subclusters based on the $D_{P}$ coefficient and unweighted average linkage algorithm.

The 56 mycobacteria fell into 12 distinct clusters (Fig. 1). The largest, cluster 7, accommodated 15 of the 16 strains received as $M$. farcinogenes. These strains fused at the $85 \% S$-level to form a distinct and homogeneous taxon which shared its highest similarities with phena containing slow growing marker strains of $M$. avium, $M$. gastri, $M$. kansasii, $M$. marinum and $M$. scrofulaceum. Cluster 5 , which contained the three $M$. vaccae markers, also clustered with the phena encompassing the slow growing strains. The remaining fast growing mycobacteria were recovered in clusters assigned to two broad groups. The first, formed at the $76 \% \mathrm{~S}$-level, included clusters 8,9 and 10 , each of which was defined at the $85 \% \mathrm{~S}$-level, and were equated with $M$. senegalense, $M$. chelone $i$ and $M$. fortuitum, respectively. Cluster 8 contained all 15 strains of $M$. senegalense and the remaining strain (GA969) received as $M$. farcinogenes. The marker strains of $M$.phlei and M. smegmatis formed clusters 11 and 12 which united at the $80 \% S$-level to give the second group.

\section{Clustering of strains using the $D_{P}$ and $S_{J}$ coefficient with the UPGMA algorithm}

The composition of the clusters obtained in the $D_{P} /$ UPGMA analysis differed only marginally from that obtained in the corresponding $S_{S M}$ analysis. The composition of both the clusters and subclusters recovered in the $S_{J}$ analysis was identical to that found in the $S_{S M} /$ UPGMA analysis. The arrangement of clusters was, however, influenced by the resemblance coefficient used (Figs 1 and 3). In the $D_{P}$ analysis, the Mycobacterium and Nocardia strains were again separated into aggregate phena but the homogeneous and distinct $M$. farcinogenes phenon shared a marginally higher affinity with the $M$. chelonei $M$. fortuitum $/ M$. senegalense group than with the taxon composed of the $M$. avium, $M$. kansasii, $M$. marinum and $M$. scrofulaceum clusters (Fig. 2). Further, the $M$. vaccae cluster was no longer classified with 


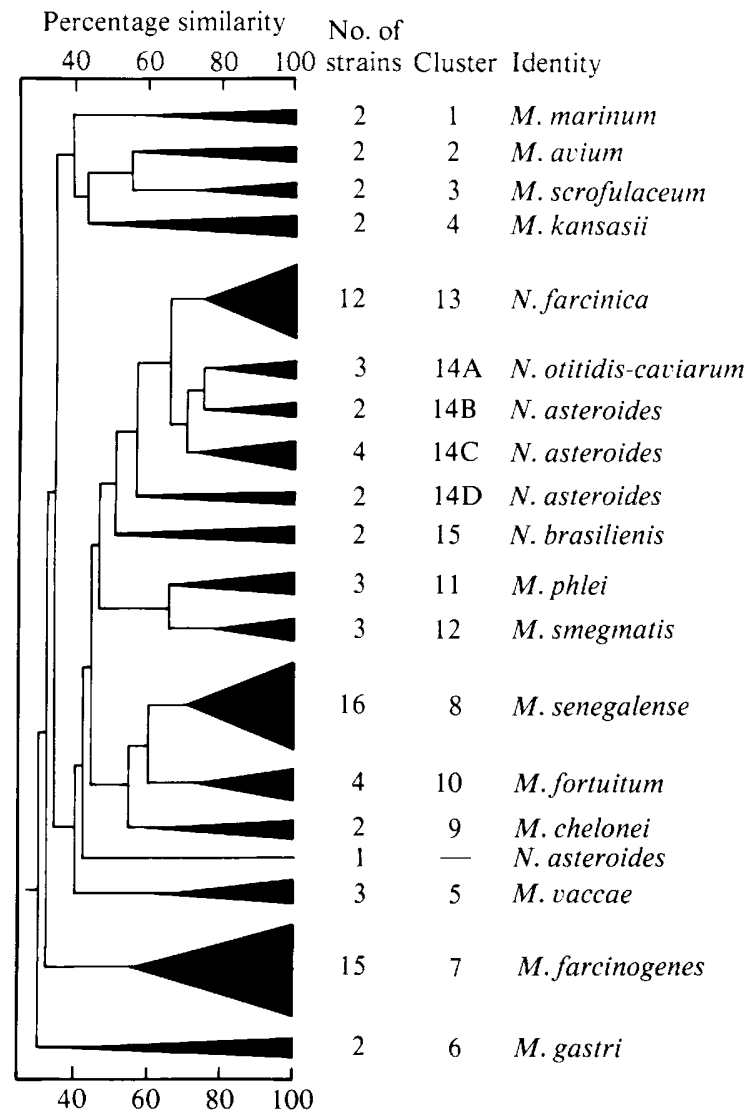

Fig. 3. A simplified dendrogram showing the relationships between clusters and subclusters based on the $S_{J}$ coefficient and unweighted average linkage algorithm.

these slow growing taxa, but was associated with the $M$. phlei/M. smegmatis group. In the $S_{J}$ analysis the Nocardia strains formed a recognizable aggregate phenon which split the Mycobacterium clusters into two parts (Fig. 3). The $M$. farcinogenes cluster was again marginally closer to the $M$. chelonei/ $M$. fortuitum $/ M$. senegalense group than to the phenon composed of the $M$. avium, $M$. kansasii, $M$. marinum and $M$. scrofulaceum clusters. The $M$. vaccae cluster was now loosely associated with the $M$. chelonei group, while $M$. gastri was recovered as a distinct cluster.

Of the eighty-two test strains, only five were assigned to different clusters in the $D_{P}$ analysis as compared with the $S_{S M} /$ UPGMA classification. The $M$. fortuitum cluster was, however, recovered as two subclusters in the $D_{P} /$ UPGMA study. Subcluster 10A contained $M$. fortuitum GA023, M. senegalense GA816 and GB043 and subcluster 10B the three remaining $M$. fortuitum strains and $M$. gastri GA363. The second $M$. gastri strain, GA447, joined the $M$. senegalense strains in cluster 8 . The final strain, $N$. asteroides GA003, previously a single member cluster, fell into subcluster 14B which also contained $N$. asteroides GA986 from subcluster 14C. Nocardia asteroides GA869, classified with the $N$. otitidis-caviarum strains of subcluster $14 \mathrm{~A}$ in the earlier analysis, now joined the type strain of $N$. asteroides (GA875) to give subcluster 14D. Nocardia asteroides GA979, previously with subcluster 14D, fell into subcluster 14C.

Characterization of Mycobacterium farcinogenes, Mycobacterium senegalense and related taxa

The characteristics of $N$. farcinica and the Mycobacterium species defined in the $S_{S M} /$ UPGMA analysis are shown in Table 2 . Characters potentially useful for differentiating $M$. farcinogenes and $M$. senegalense from one another and from some related taxa are shown in Table 3. 
Table 2. Comparison of the characteristics of Mycobacterium farcinogenes, Mycobacterium senegalense and some related taxa

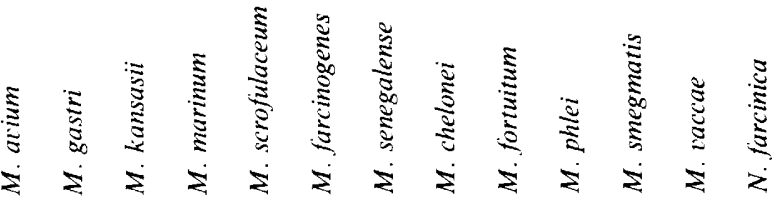

$$
\begin{aligned}
& \begin{array}{llllllllllllll}
\text { Cluster no. . . } & 2 & 6 & 4 & 1 & 3 & 7 & 8 & 9 & 10 & 11 & 12 & 5 & 13
\end{array}
\end{aligned}
$$

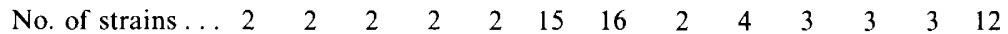

\section{Character*}

Colonial characters:

Colonies white/grey

Colonies yellow

Colonies orange/red

Colonies $\leqslant 2 \mathrm{~mm}$ diam.

Colonies $\leqslant 10 \mathrm{~mm}$ diam.

Aerial hyphae sparse

Aerial hyphae moderate

Aerial hyphae abundant

Colonies glossy

Colonies smooth

Colonies folded

Margin elevated

Margin filamentous

Elevation concave

Colonies easily detached from agar

Growth into agar moderate

Growth into agar extensive

Colonies emulsifiable

Colonies highly emulsifiable

Colonies ropy

Colonies coarse

Colonies very coarse

$\begin{array}{rrrrrrrrrrrrr}2 & 2 & 2 & 0 & 0 & 15 & 16 & 2 & 3 & 0 & 0 & 0 & 0 \\ 0 & 0 & 0 & 2 & 2 & 0 & 0 & 0 & 1 & 3 & 3 & 3 & 10 \\ 0 & 0 & 0 & 0 & 0 & 0 & 0 & 0 & 0 & 0 & 0 & 0 & 2 \\ 2 & 0 & 2 & 1 & 1 & 8 & 1 & 0 & 0 & 0 & 0 & 0 & 0 \\ 0 & 0 & 0 & 0 & 0 & 0 & 0 & 0 & 0 & 1 & 1 & 0 & 1 \\ 0 & 0 & 0 & 0 & 0 & 10 & 9 & 0 & 0 & 0 & 0 & 0 & 8 \\ 0 & 0 & 0 & 0 & 0 & 3 & 0 & 0 & 0 & 0 & 0 & 0 & 6 \\ 0 & 0 & 0 & 0 & 0 & 0 & 0 & 0 & 0 & 0 & 0 & 0 & 1 \\ 1 & 2 & 1 & 1 & 2 & 5 & 11 & 1 & 4 & 0 & 3 & 3 & 8 \\ 1 & 0 & 0 & 1 & 1 & 0 & 0 & 1 & 0 & 0 & 0 & 3 & 0 \\ 1 & 1 & 2 & 1 & 1 & 15 & 16 & 1 & 4 & 3 & 3 & 0 & 12 \\ 0 & 0 & 0 & 0 & 0 & 3 & 0 & 0 & 0 & 0 & 0 & 0 & 4 \\ 0 & 0 & 0 & 0 & 0 & 0 & 0 & 0 & 0 & 0 & 0 & 0 & 10 \\ 0 & 0 & 0 & 0 & 0 & 0 & 0 & 0 & 0 & 0 & 0 & 0 & 1 \\ 0 & 0 & 0 & 0 & 0 & 11 & 0 & 0 & 0 & 0 & 0 & 0 & 0 \\ 0 & 0 & 0 & 0 & 0 & 0 & 1 & 0 & 0 & 0 & 0 & 0 & 10 \\ 0 & 0 & 0 & 0 & 0 & 0 & 0 & 0 & 0 & 0 & 0 & 0 & 7 \\ 2 & 2 & 1 & 1 & 2 & 0 & 5 & 2 & 4 & 2 & 3 & 3 & 7 \\ 1 & 1 & 0 & 1 & 2 & 0 & 0 & 2 & 2 & 0 & 2 & 0 & 3 \\ 1 & 0 & 0 & 0 & 0 & 0 & 0 & 0 & 0 & 0 & 0 & 0 & 0 \\ 0 & 0 & 0 & 1 & 0 & 15 & 8 & 0 & 2 & 3 & 0 & 0 & 8 \\ 0 & 0 & 0 & 0 & 0 & 13 & 1 & 0 & 0 & 0 & 0 & 0 & 0\end{array}$

Biochemical tests:

Arylsulphatase

Catalase positive

Catalase strongly positive

$\beta$-lactamase after $20 \mathrm{~min}$ :

Positive

Moderately positive

Highly positive

$\beta$-lactamase after $60 \mathrm{~min}$ :

Positive

Moderately positive

Highly positive

Nitrite reductase positive

Nitrite reductase highly positive

Nitrophenoloxidase

$\begin{array}{rrrrrrrrrrrrr}0 & 2 & 0 & 1 & 0 & 1 & 15 & 2 & 4 & 0 & 0 & 3 & 0 \\ 0 & 0 & 2 & 2 & 2 & 0 & 14 & 0 & 3 & 2 & 0 & 3 & 10 \\ 0 & 0 & 0 & 0 & 0 & 0 & 1 & 0 & 0 & 0 & 0 & 1 & 0 \\ & & & & & & & & & & & & \\ 0 & 1 & 2 & 0 & 0 & 10 & 12 & 2 & 1 & 2 & 3 & 0 & 12 \\ 0 & 0 & 0 & 0 & 0 & 5 & 6 & 0 & 0 & 1 & 3 & 0 & 12 \\ 0 & 0 & 0 & 0 & 0 & 4 & 2 & 0 & 0 & 1 & 2 & 0 & 8 \\ 0 & 1 & 2 & 0 & 0 & 14 & 14 & 2 & 3 & 3 & 3 & 3 & 12 \\ 0 & 1 & 0 & 0 & 0 & 9 & 13 & 2 & 2 & 3 & 3 & 2 & 12 \\ 0 & 1 & 0 & 0 & 0 & 7 & 8 & 2 & 1 & 2 & 3 & 0 & 12 \\ 0 & 1 & 2 & 0 & 2 & 10 & 15 & 0 & 4 & 3 & 3 & 2 & 3 \\ 0 & 0 & 2 & 0 & 0 & 2 & 13 & 0 & 4 & 3 & 2 & 0 & 0 \\ 0 & 0 & 0 & 0 & 0 & 0 & 0 & 0 & 0 & 0 & 0 & 0 & 9\end{array}$

Degradation tests:

\section{Testosterone}

Tyrosine

Resistance to $\left(\mu \mathrm{g} \mathrm{ml}^{-1}\right)$ :

Capreomycin, 10

$$
\begin{array}{r}
20 \\
40 \\
160 \\
320
\end{array}
$$

Dapsone, 100

Ethambutol, 4 
Table 2. (continued)

\section{Character*}

Isoniazid, 0.25

0.50

$2 \cdot 00$

Lysozyme, 50

100

200

Penicillin, 66 i.u. $\mathrm{ml}^{-1}$

Prothionamide, 10

20
40
160

320

Rifampin, 20

Streptomycin, 8

$$
\begin{aligned}
& 16 \\
& 64
\end{aligned}
$$

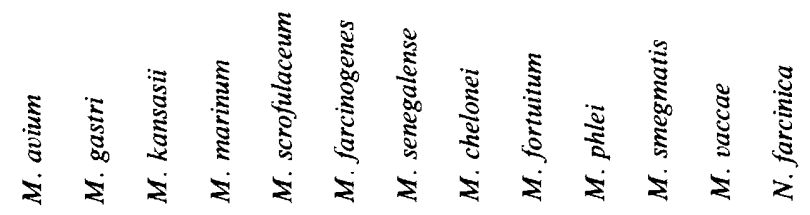

$\begin{array}{llllllllllllll}\text { Cluster no. . } & 2 & 6 & 4 & 1 & 3 & 7 & 8 & 9 & 10 & 11 & 12 & 5 & 13\end{array}$ $\begin{array}{llllllllllllll}\text { No. of strains ... } & 2 & 2 & 2 & 2 & 2 & 15 & 16 & 2 & 4 & 3 & 3 & 3 & 12\end{array}$

$\begin{array}{lllllllllllll}2 & 2 & 2 & 2 & 2 & 14 & 16 & 2 & 4 & 3 & 3 & 3 & 12\end{array}$

$\begin{array}{lllllllllllll}2 & 0 & 2 & 2 & 2 & 14 & 16 & 2 & 4 & 3 & 3 & 3 & 12\end{array}$

$\begin{array}{lllllllllllll}2 & 0 & 2 & 2 & 2 & 14 & 16 & 2 & 4 & 3 & 3 & 0 & 12\end{array}$

$\begin{array}{lllllllllllll}1 & 2 & 1 & 2 & 2 & 14 & 16 & 2 & 4 & 1 & 1 & 3 & 12\end{array}$

$\begin{array}{lllllllllllll}1 & 2 & 0 & 2 & 2 & 14 & 10 & 2 & 3 & 0 & 1 & 2 & 12\end{array}$

$\begin{array}{lllllllllllll}0 & 2 & 0 & 2 & 0 & 0 & 9 & 1 & 3 & 0 & 0 & 1 & 12\end{array}$

$\begin{array}{lllllllllllll}2 & 2 & 2 & 2 & 2 & 12 & 16 & 2 & 4 & 3 & 3 & 3 & 12\end{array}$

$\begin{array}{lllllllllllll}2 & 1 & 2 & 2 & 2 & 15 & 16 & 2 & 4 & 3 & 3 & 3 & 12\end{array}$

$\begin{array}{lllllllllllll}2 & 1 & 0 & 0 & 2 & 15 & 16 & 2 & 4 & 3 & 3 & 3 & 12\end{array}$

$\begin{array}{lllllllllllll}2 & 0 & 0 & 0 & 2 & 14 & 14 & 2 & 4 & 3 & 3 & 1 & 12\end{array}$

$\begin{array}{lllllllllllll}0 & 0 & 0 & 0 & 0 & 2 & 2 & 0 & 4 & 1 & 2 & 0 & 12\end{array}$

$\begin{array}{lllllllllllll}0 & 0 & 0 & 0 & 0 & 0 & 0 & 0 & 0 & 0 & 0 & 0 & 12 \\ 0 & 0 & 1 & 0 & 0 & 9 & 2 & 1 & 4 & 0 & 3 & 0 & 12\end{array}$

$\begin{array}{lllllllllllll}1 & 0 & 0 & 2 & 2 & 12 & 16 & 2 & 4 & 0 & 0 & 0 & 12\end{array}$

$\begin{array}{rrrrrrrrrrrrr}1 & 0 & 0 & 0 & 0 & 5 & 16 & 2 & 4 & 0 & 0 & 0 & 12 \\ 0 & 0 & 0 & 0 & 0 & 0 & 12 & 2 & 4 & 0 & 0 & 0 & 6\end{array}$

Growth in presence of:

Crystal violet $(0.001 \%, \mathrm{w} / \mathrm{v})$

Good

Very good

Phenol $(0 \cdot 1 \%, \mathrm{w} / \mathrm{v})$

Good

Very good

Sodium azide $(0.01 \%, w / v)$

Good

Very good

Potassium tellurite $(0.04 \%$, w/v)

Good

Very good

Sodium chloride $(3 \%, \mathrm{w} / \mathrm{v})$

Sodium chloride $(5 \%, w / v)$

Sodium chloride $(7 \%, \mathrm{w} / \mathrm{v})$

Sodium chloride $(10 \%, \mathrm{w} / \mathrm{v}$

Sodium chloride (L-J; 7\%, w/v)

$\begin{array}{lllllllllllll}2 & 0 & 2 & 1 & 2 & 1 & 2 & 0 & 4 & 1 & 3 & 0 & 2 \\ 0 & 0 & 1 & 0 & 2 & 0 & 0 & 0 & 4 & 0 & 2 & 0 & 0\end{array}$

$\begin{array}{lllllllllllll}0 & 0 & 0 & 0 & 0 & 0 & 0 & 0 & 4 & 3 & 3 & 0 & 12\end{array}$

$\begin{array}{lllllllllllll}0 & 0 & 1 & 0 & 0 & 0 & 4 & 0 & 4 & 3 & 3 & 2 & 12\end{array}$

Growth at:

pH 4.0

pH 4.4

pH $5 \cdot 0$

pH 9.5

$\mathrm{pH} 10.2$

pH 10.8

$12{ }^{\circ} \mathrm{C}$, Good

Very good

$50^{\circ} \mathrm{C}$, Good

$45^{\circ} \mathrm{C},(\mathrm{L}-\mathrm{J})$

$$
\text { Very good }
$$

Growth on:

Sabouraud agar, Good

Very good

$\begin{array}{lllllllllllll}2 & 2 & 2 & 1 & 2 & 2 & 16 & 1 & 4 & 3 & 3 & 1 & 12 \\ 2 & 2 & 0 & 0 & 1 & 1 & 16 & 1 & 4 & 2 & 3 & 1 & 12\end{array}$

Growth after:

$24 \mathrm{~h}$

$5 \mathrm{~d}$

$\begin{array}{rrrrrrrrrrrrr}0 & 0 & 0 & 0 & 0 & 0 & 2 & 0 & 4 & 3 & 3 & 2 & 10 \\ 1 & 0 & 1 & 0 & 0 & 0 & 16 & 0 & 4 & 3 & 3 & 3 & 12\end{array}$ 
Table 2. (continued)

Cluster no.....
No. of strains ...
Character*

* None of the strains degraded adenine, blood, elastin, guanine, hypoxanthine, starch or xanthine, produced diffusible exopigments or brown colonies, grew at $\mathrm{pH} 3.3$ or 11.3 , grew on Rogosa medium, but all grew in the presence of crystal violet $(0.0001 \%, w / v)$, phenol $(0.01,0.001 \%, w / v)$ or sodium azide $(0.001 \%, w / v)$.

\section{Table 3. Characters with the greatest resolving power for differentiating Mycobacterium} farcinogenes, Mycobacterium senegalense and some related taxa

Key: + , more than $85 \%$ of strains positive; - , more than $85 \%$ of strains negative; d, strains 16 to $84 \%$ positive.

Character

Colonies white/grey

Arylsulphatase

Catalase positive

Testosterone

Sensitivity to $\left(\mu \mathrm{g} \mathrm{ml}^{-1}\right)$

Capreomycin, 10

Dapsone, 100

Ethambutol, 32

Prothionamide, 160

Sodium chloride $(5 \%, \mathrm{w} / \mathrm{v})$

Potassium tellurite $(0.04 \%$ w/v)

Growth at pH 5.0

Growth on Sabouraud agar

Growth after $5 \mathrm{~d}$

\begin{tabular}{|c|c|c|c|}
\hline$\frac{\tilde{\Xi}}{\frac{\Xi}{3}}$ & 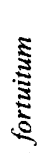 & 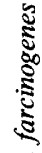 & \\
\hline$\Sigma$ & $\Sigma$ & $\dot{\Sigma}$ & \\
\hline+ & $\mathrm{d}$ & + & \\
\hline+ & + & - & \\
\hline- & $\mathrm{d}$ & - & \\
\hline- & + & + & \\
\hline+ & + & - & \\
\hline+ & + & - & \\
\hline+ & + & - & \\
\hline- & + & - & \\
\hline- & + & - & \\
\hline- & + & - & \\
\hline $\mathrm{d}$ & + & - & \\
\hline$d$ & + & - & \\
\hline $\mathrm{d}$ & + & - & \\
\hline & + & - & \\
\hline
\end{tabular}

\section{DISCUSSION}

The numerical phenetic classification obtained was by and large the same irrespective of the resemblance coefficient used $\left(D_{P}, S_{J}, S_{S M}\right)$ and was only marginally affected by the test error of around $2.5 \%$. Agreement between classifications based on different numerical techniques is a sign of good taxonomy (Austin \& Colwell, 1977; Goodfellow et al., 1978) and means that the numerical data can be interpreted with confidence.

In all three analyses, the Nocardia strains, including $N$. farcinica, formed an aggregate phenon distinct from the mycobacteria. The recovery of $N$. farcinica among the nocardiae and $M$. farcinogenes and $M$. senegalense with the mycobacteria is in agreement with previous chemical and serological analyses (Tsukamura, 1969; Ridell, 1975; Orchard \& Goodfellow, 1980; Ridell et al., 1982). It was also encouraging to find that these taxa can be readily distinguished by a number of biochemical and physiological tests. 
The relationships between the Mycobacterium clusters were to some extent affected by the coefficients employed, though in all cases relatively high overall similarities were found between $M$. chelonei, $M$. fortuitum and $M$. senegalense, and between $M$. phlei and $M$. smegmatis as well as between $M$. avium, $M$. kansasii, $M$. marinum and $M$. scrofulaceum. The $M$. farcinogenes phenon was not closely related to any of these aggregate groups. It was marginally associated with the taxa containing slow growing mycobacteria in the $S_{S M}$ analysis, with $M$. chelonei, $M$. fortuitum and $M$. senegalense in the $D_{P}$ analysis, but formed a distinct cluster in the $S_{J}$ study. The close similarity found between $M$. gastri, $M$. fortuitum and $M$. senegalense in the $D_{P}$ analysis is a reflection of the relatively small number of positive responses shown by the former. It has already been demonstrated (Goodfellow et al., 1978) that when organisms which yield many positive responses are compared with less vigorous strains, the pattern difference can be artificially small.

The recovery of the $N$. farcinica strains in a homogeneous phenon distinct from Nocardia clusters is in excellent agreement with previous numerical phenetic classifications (Tsukamura, 1969; Schaal \& Reutersberg, 1978; Orchard \& Goodfellow, 1980) and with data from DNA pairing experiments (Mordarski et al., 1977, 1978). The numerical data also provide further evidence of the heterogeneity of $N$. asteroides (Tsukamura, 1969; Kurup \& Schmitt, 1973; Mordarski et al., 1977; Schaal \& Reutersberg, 1978; Orchard \& Goodfellow, 1980).

The most reliable classifications are those in which relationships between taxa are supported by different kinds of independent taxonomic criteria. In mycobacterial systematics, both numerical and comparative immunodiffusion analyses have proved to be effective in the characterization and delineation of species (Lind et al., 1980; Goodfellow \& Wayne, 1982). The recovery of the $M$. farcinogenes and $M$. senegalense in distinct and homogeneous clusters equivalent in rank with established species of Mycobacterium is consistent with their recognition as distinct species (Chamoiseau, 1973; Goodfellow \& Wayne, 1982). In addition, a number of biochemical, growth and inhibition tests were found to be of presumptive value for the separation of $M$. farcinogenes and $M$. senegalense. In contrast, comparative immunodiffusion studies show that $M$. farcinogenes, $M$. senegalense and $M$. fortuitum are not only very similar serologically but are difficult to separate into distinct species (Ridell, 1981; Ridell et al., 1982). The affinity between these two taxa is supported by the results of mycolic acid analyses, though TLC analysis of mycobacterial mycolates does not yield data sufficiently sensitive for species definition (Minnikin \& Goodfellow, 1980; Ridell et al., 1982). Two dimensional TLC of whole organism methanolysates does, however, provide a reliable way of distinguishing $M$. chelonei from $M$. farcinogenes, $M$. fortuitum and $M$. senegalense and all other mycobacteria examined to date (Goodfellow \& Minnikin, 1981 b; Minnikin et al., 1982).

The present study has gone some way towards clarifying the systematics of $M$. farcinogenes, $M$. senegalense, $N$. farcinica and some related taxa. Additional work is, however, required to explain the apparently conflicting results obtained in the numerical and serological studies on $M$. farcinogenes and $M$. senegalense. Representative strains of these taxa should be examined using the DNA-DNA pairing method, for especially good congruence has been found between DNA pairing and numerical phenetic data in previous studies on actinomycetes (Mordarski et al., 1981).

The authors are indebted to colleagues who kindly provided strains (Table 1), to Carole Todd for help with the computation and to Vivianne Sundaeus and Gun Wallerström for technical assistance. Both authors wish to thank the British Council for travel grants and M.R. is also grateful for support from the Swedish National Association against Heart and Chest Disease.

\section{REFERENCES}

Austin, B. \& Colwell, R. R. (1977). Evaluation of some coefficients for use in numerical taxonomy of microorganisms. International Journal of Systematic Bacteriology 27, 204-210.

Backelin, B., Lind, A. \& Ridell, M. (1973). A new test method for demonstrating $\beta$-lactamase activity among mycobacteria and nocardiae. Tubercle 54, 297-307.

BöNICKE, R. \& JuHasz, S. E. (1965). Methods of differentiation of the genus Mycobacterium from the genus Nocardia. Bulletin of the International Union against Tuberculosis 36, 14-21. 
Chamoiseau, G. (1969). De l'étiologie du farcin de zébus tchadiens: nocardiose ou mycobactériose? IÉtude bactériologique et biochimique. Revue d'élevage et de médecine vétérinaire des pays tropicaux 22 , 195-204.

Chamoiseau, G. (1972). De l'étiologie de farcin de zébus tchadiens: nocardiose ou mycobactériose? III-Activité amidasique. Revue d'élevage et de médecine vétérinaire des pays tropicaux 25, 191-194.

Chamoiseau, G. (1973). Mycobacterium farcinogenes agent causal du farcin du boeuf en Afrique. Annales de Microbiologie 124A, 215-222.

Chamolseau, G. (1979). Etiology of farcy in african bovines: nomenclature of the causal organisms Mycobacterium farcinogenes Chamoiseau and $\mathrm{Myco}$ bacterium senegalense (Chamoiseau) comb. nov. International Journal of Systematic Bacteriology 29, 407-410.

DAvID, H. (1976). Bacteriology of the mycobacteriosis. U.S. Public Health Service Publication No. CDC 768316.

Goodfellow, M. \& Minnikin, D. E. (1981a). The genera Nocardia and Rhodococcus. In The Prokaryotes: $\boldsymbol{A}$ Handbook of Habitats, Isolation and Identification of Bacteria, pp. 2016-2027. Edited by M. P. Starr, H. Stolp, H. G. Trüper, A. Balows \& H. G. Schlegel. Berlin: Springer Verlag.

Goodfellow, M. \& MiNNIKIN, D. E. (1981b). Identification of Mycobacterium chelonei by thin-layer chromatographic analysis of whole-organism methanolysates. Tubercle 62, 285-287.

Goodfellow, M. \& Wayne, L. G. (1982). Taxonomy and nomenclature. In Biology of the Mycobacteria, Vol. I, pp. 472-521. Edited by C. Ratledge \& J. L. Stanford. London: Academic Press.

Goodfellow, M., Orlean, P. A. B., Collins, M. D., Alshamaony, L. \& Minnikin, D. E. (1978). Chemical and numerical taxonomy of strains received as Gordona aurantiaca. Journal of General Microbiology 109, 57-68.

GORDON, R. E. (1967). The taxonomy of soil bacteria. In The Ecology of Soil Bacteria, pp. 293-321. Edited by T. R. G. Gray \& D. Parkinson. Liverpool: Liverpool University Press.

GORDON, R. E. \& BARNETT, D. A. (1977). Resistance to rifampin and lysozyme of strains of some species of Mycobacterium and Nocardia as a taxonomic tool. International Journal of Systematic Bacteriology 27, 176-178.

GoRDON, R. E. \& MiHM, J. M. (1957). A comparative study of some strains received as nocardiae. Journal of Bacteriology 73, 15-27.

KubiCA, G. \& PoOL, G. L. (1960). Studies on catalase activity of acid-fast bacilli. American Review of Respiratory Diseases 81, 387-391.

Kurup, P. V. \& SchmitT, J. A. (1973). Numerical taxonomy of Nocardia. Canadian Journal of Microbiology 19, 1035-1048.

LiND, A., OUCHTERLONY, Ö. \& Ridell, M. (1980). Mycobacterial antigens. In Infektionskrankheiten und ihre Erreger: Mykobakterien und mykobakterielle Krankheiten, Band 4, Teil 1, pp. 245-303. Edited by G. Meissner \& A. Schmiedel. Jena: Fischer Verlag.

Magnusson, M. (1976). Sensitin tests as an aid in the taxonomy of Nocardia and its pathogenicity. In The Biology of the Nocardiae, pp. 236-265. Edited by M.
Goodfellow, G. H. Brownell \& J. A. Serrano. London: Academic Press.

Magnusson, M. \& MARIAT, F. (1968). Delineation of Nocardia farcinica by delayed type skin reactions on guinea pigs. Journal of General Microbiology 51, 151158.

Minnikin, D. E. \& Goodfellow, M. (1980). Lipid composition in the classification and identification of acid-fast bacteria. In Microbiological Classification and Identification, pp. 189-256. Edited by M. Goodfellow \& R. G. Board. London: Academic Press.

MinNikin, D. E., Minnikin, S. M., Goodfellow, M. \& STANFORD, J. L. (1982). The mycolic acids of Mycobacterium chelonei. Journal of General Microbiology 128, 817-822.

Mordarski, M., SchaAl, K. P., Szyba, K., Pulverer, G. \& TKACZ, A. (1977). Classification of Nocardia asteroides and allied taxa based upon deoxyribonucleic acid reassociation. International Journal of Systematic Bacteriology 27, 66-70.

Mordarski, M., SchaAl, K. P., Tkacz, A., Pulverer, G., Szyba, K. \& Goodfellow, M. (1978). Deoxyribonucleic acid base composition and homology studies on Nocardia. Zentralblatt für Bakteriologie, Parasitenkunde, Infektionskrankheiten und Hygiene (I. Abteilung), Supplement 6, 43-51.

Mordarski, M., Kaszen, I., TKaCZ, A., GoodFellow, M., Alderson, G., SchaAl, K. P. \& Pulverer, G. (1981). Deoxyribonucleic acid pairing in the classification of the genus Rhodococcus. Zentralblatt für Bakteriologie, Mikrobiologie und Hygiene. (I. Abteilung), Supplement 11, 25-31.

OrChaRd, V. A. \& GoOdFEllow, M. (1980). Numerical classification of some named strains of Nocardia asteroides and related isolates from soil. Journal of General Microbiology 118, 295-312.

Ridell, M. (1975). Taxonomic study of Nocardia farcinica using serological and physiological characters. International Journal of Systematic Bacteriology 25, 124-132.

RIDELl, M. (1981). Immunodiffusion studies of $M y c o-$ bacterium, Nocardia and Rhodococcus for taxonomic purposes. Zentralblatt für Bakteriologie, Mikrobiollogie und Hygiene. (I. Abteilung), Supplement 11, 235-241.

Ridell, M., Goodfellow, M., Minnikin, D. E., Minnikin, S. M. \& Hutchinson, I. G. (1982). Classification of Mycobacterium farcinogenes and Mycobacterium senegalense by immunodiffusion and thin-layer chromatography of long chain components. Journal of General Microbiology 128, 12991307.

SCHAAL, K. P. \& Reutersberg, H. (1978). Numerical taxonomy of Nocardia asteroides. Zentralblatt für Bakteriologie, Parasitenkunde, Infektionskrankheiten und Hygiene (I. Abteilung), Supplement 6, 53-62.

SNEATH, P. H. A. (1957). The applications of computers to taxonomy. Journal of General Microbiology 17, 201-226.

SNEATH, P. H. A. (1968). Vigour and pattern in taxonomy. Journal of General Microbiology 54, $1-11$.

SNEATH, P. H. A. \& SoKal, R. R. (1973). Numerical Taxonomy. The Principles and Practice of Numerical Classification. San Francisco: W. H. Freeman.

SOKal, R. R. \& Michener, C. D. (1958). A statistical 
method for evaluating systematic relationships. Kansas University Science Bulletin 38, 1409-1438.

Tsukamura, M. (1969). Numerical taxonomy of the genus Nocardia. Journal of General Microbiology 56, 265-287.

VirTANEN, S. A. (1960). A study of nitrate reduction by mycobacteria. Acta tuberculosea scandinavica, Supplement 48, 1-199.

WAYNE, L. G. (1961). Recognition of Mycobacterium fortuitum by means of a three-day phenolphthalein sulfatase test. The American Journal of Clinical Patho$\log y$ 36, 185-187.

WAYNe, L. G., KRIChevsKy, E. J, LOVE, L. L. JOHNSON, R. \& KRICHEVSKY, M. I. (1980). Taxonomic probability matrix for use with slowly growing mycobacteria. International Journal of Systematic Bacteriology 30, 528-538.

WishaRT, D. (1978). Clustan User Manual, Version IC, release 2, 3rd edn. Edinburgh: Edinburgh University Program Library Unit. 